\title{
Revista Brasileira de Enfermagem REBEn \\ A dor na Unidade Neonatal sob a perspectiva dos profissionais de enfermagem de um hospital de Ribeirão Preto-SP
}

Pain at the Neonatal Unit under a perspective of nursing staff from a University hospital, Ribeirão Preto, SP, Brazil

El dolor en la Unidad Neonatal por la perspectiva de la practica de enfermería en un hospital de Ribeirão Preto, SP, Brasil

\section{Carmen Gracinda Silvan Scochi}

Professor Titular do Departamento de Enfermagem Materno Infantil e Saúde Pública (DEMISP) da Escola de Enfermagem de Ribeirão Preto - USP (EERP-USP). cscochi@eerp.usp.br

\section{Mariângela Carletti}

Enfermeira da Unidade de Cuidado Intensivo Neonatal do Hospital de Clínicas da Faculdade de Medicina de Ribeirão Preto da Universidade de São Paulo. Bolsista de Iniciação Científica PET/CAPES 2003/2004.

Rachel Nunes

Bolsista de Iniciação Científica PET/CAPES 2003/2004.

\section{Maria Cândida de Carvalho Furtado}

Enfermeira. Especialista em laboratório junto ao DEMISP-EERP-USP.

Adriana Moraes Leite

Professor Doutor do DEMISP-EERP-USP.

Pesquisa vinculada ao projeto com financiamento do CNPq - bolsa Produtividade em Pesquisa e Edital Universal 19/2004.

\section{RESUMO}

Estudo descritivo qualitativo buscou descrever a compreensão, a avaliação e o manejo da dor no RN sob cuidado intensivo. Dezesseis profissionais de enfermagem identificaram a dor mediante alterações comportamentais e fisiológicas. Consideram ineficaz o uso da escala NIPS na prática clínica. Apontam dificuldades em diferenciar manifestações de dor e estresse no cotidiano profissional. Preocupam-se com o manejo adequado da dor e buscam o conhecimento desta temática ainda de maneira incipiente, em sua maioria, mediante a vivência adquirida no cuidado neonatal e a troca de experiências com outros profissionais. Assim, acredita-se que a instrumentalização através de acesso à literatura específica e cursos de capacitação sobre a temática otimizariam o manejo, contribuindo na melhoria da assistência e qualidade de vida dos bebês.

Descritores: Dor; Recém-nascido; Enfermagem pediátrica.

\section{ABSTRACT}

This descriptive study from a qualitative approach aims to describe how the nursing team understands pain assessment and management in newborns at a Neonatal Intensive Care Unit (NICU). The subjects are 16 nursing professionals. The nursing staff identifies pain when behavioral and physiological changes are present. They use the NIPS scale, although it is not effective in clinical practice. Subjects reveal difficulties in making a difference between pain and stress responses in daily work. They are worried about correct pain management in newborns. The search of knowledge about pain is still incipient, and subjects mostly obtain it through their experiences in newborn care and by exchanging experiences with other professionals. The nursing team needs greater access to specific literature about neonatal pain and training courses that can optimize pain management, thus contributing to a better care capacity and to the newborn's quality of life.

Descriptors: Pain; Newborn; Pediatric nursing.

\section{RESUMEN}

La finalidad de este estudio descriptivo con aproximación cualitativa es describir como los profesionales de enfermería comprenden la cuestión del dolor, su evaluación y manejo en recién-nacidos (RNs) sometidos al cuidado intensivo. Participaron del estudio 16 profesionales de enfermería. La enfermería identifica el dolor por medio de alteraciones comportamentales y fisiológicas. Utilizan la escala NIPS, a pesar de que esta no es considerada eficaz en la práctica clínica. Los participantes muestran dificultades para diferenciar manifestaciones de dolor y estrés en el día a día del trabajo. Tienen preocupación por el manejo adecuado del dolor en los RNs. La búsqueda de conocimiento sobre el dolor todavía ocurre de manera incipiente y se obtiene, en la mayoría de las veces mediante la vivencia adquirida en el cuidado de los RNs y el cambio de experiencias con otros profesionales. Es necesario instrumentalizar mejor al equipo de enfermería del hospital escuela a través del mayor acceso a la literatura específica sobre el dolor neonatal y de cursos de capacitación para que puedan optimizar el manejo del dolor en la unidad neonatal, contribuyendo con la mejoría de la atención y con la calidad de vida de los bebés.

Descriptores: Dolor; Recién-nacidos; Enfermería pediatrica.

Scochi CGS, Carletti M, Nunes R, Furtado MCC, Leite AM. A dor na Unidade Neonatal sob a perspectiva dos profissionais de enfermagem de um hospital de Ribeirão Preto-SP. Rev Bras Enferm 2006 mar-abr; 59(2): 188-94.

\section{INTRODUÇÃO}

Os estudos sobre dor em recém-nascidos (RNs) têm evoluído desde a metade da década de 80 do século passado. Atualmente é plenamente aceito que tanto o RN a termo como o pré-termo apresentam todos os componentes anatômicos, funcionais e neuroquímicos essenciais para a nocicepção, ou seja, para a recepção, transmissão e integração do estímulo doloroso ${ }^{(1,2)}$.

Sendo assim, com o desenvolvimento do conhecimento da fisiologia da dor no RN, os pesquisadores
Submissão: 04/05/2005

Aprovação: 30/10/2005 
têm percebido a importância do seu estudo da dor nessa população.

Uma das questões mais importantes deste campo de conhecimento diz respeito à dificuldade de avaliação e mensuração da dor no neonato, constituindo-se em um dos maiores obstáculos para o tratamento adequado da dor nas Unidade de Cuidados Intensivos Neonatais (UCINs).

Isso se deve à ausência da comunicação verbal desses pacientes, dos seus diferentes níveis cognitivos e das suas reações similares aos inúmeros tipos de estímulos, tornando subjetiva a mensuração da dor. Sendo assim, a disponibilidade de métodos para avaliação da dor do RN é a base para o tratamento adequado da mesma e a garantia de uma assistência mais humanizada ${ }^{(3)}$.

Embora a comunidade médica aceite que o RN é capaz de sentir dor, observa-se pouca utilização de analgesia nas UCINs, devido à falha de conhecimento científico a respeito do diagnóstico e tratamento da dor na prática diária dos profissionais de saúde ${ }^{(4)}$.

É fundamental acentuar o processo de sensibilização dos profissionais, em especial os da enfermagem, para a linguagem pré-verbal dos neonatos, com a finalidade de melhorar a assistência desses pacientes submetidos a inúmeros procedimentos dolorosos ao longo das internações nas UCINs, pois estes profissionais são os principais envolvidos no manejo e nos cuidados dos RNs ${ }^{(5)}$.

Para tanto, este estudo tem como objetivo descrever como os profissionais de enfermagem compreendem a questão da dor, sua avaliação e manejo no RN submetido ao cuidado intensivo.

\section{METODOLOGIA}

Trata-se de um estudo descritivo, com abordagem qualitativa que permite uma aproximação íntima entre o sujeito que investiga e o investigado(6).

Os dados foram coletados, por meio de entrevistas semiestruturadas, na Unidade de Cuidado Intensivo Neonatal (UCIN) do Hospital das Clínicas da Faculdade de Medicina de Ribeirão Preto da Universidade de São Paulo (HCFMRP-USP), após aprovação do Comitê de Ética em Pesquisa do referido hospital. Esta unidade é composta por 20 leitos neonatais de alta complexidade, atendendo pacientes provenientes do próprio serviço, bem como aqueles advindos de outros serviços tanto do município como de outras cidades e estados, já que este é um hospital referência para a região.

Utilizou-se um roteiro estruturado em três partes, quais sejam, dados de identificação do hospital e da unidade neonatal, dados de identificação dos entrevistados e as seguintes questões norteadoras:

1 - Você acredita que o recém-nascido sente dor? E o prematuro?

\section{2 - 0 que pode causar a dor no recém-nascido?}

3 - Como você identifica/avalia a dor no recém nascido? (Quais são os sinais/manifestações que você interpreta como dor? Utiliza escalas? Ela tem sido útil para identificar a dor?)

4 - Quais são as intervenções (farmacológicas e não farmacológicas) que a enfermagem utiliza para minimizar e tratar a dor do recém-nascido?

5 - Quais são as fontes de informações que você utiliza em relação ao manejo da dor (livros, artigos publicados, orientação da equipe médica, aprendizado com outras enfermeiras, cursos/evento, etc)?

A coleta de dados foi feita mediante entrevistas gravadas, após a permissão dos sujeitos e a assinatura do Termo de Consentimento Livre e Esclarecido, no período de 05 de abril a 27 de maio de $2004 \mathrm{com} 30 \%$ do pessoal de enfermagem que assume diretamente o cuidado do neonatos de alto risco da UCIN do HCFMRP, totalizando 16 sujeitos: 03 enfermeiros, 02 residentes de enfermagem, 02 técnicos de enfermagem e 10 auxiliares de enfermagem.

A seleção do local para a realização do estudo, justifica-se pelos inúmeros procedimentos dolorosos no RN que aí ocorrem, além de ser campo de ensino e pesquisa na área de enfermagem.

\subsection{Análise dos dados}

Para análise e interpretação dos dados, utilizamos parte da técnica de análise de enunciação, ou seja, apenas a primeira etapa - a análise temática ${ }^{(7)}$.

Sendo assim, após a transcrição do material gravado e leitura do mesmo, selecionamos trechos das entrevistas, agrupando-as de acordo com a semelhança dos relatos dos entrevistados, tirando as idéias relevantes. Para facilitar a compreensão dos destaques nas falas, optamos pela seguinte padronização ou legenda: $\left\{\_\right\}$pausa durante a fala, /.../ recortes de outras falas, ... recortes na mesma fala e ( ) observações complementares contendo conteúdos e comportamentos não verbais para situar as falas.

Em respeito ao anonimato dos participantes e para evitarmos que sua identificação fosse feita através de informações, os mesmos foram numerados em ordem crescente, sendo codificados da seguinte maneira: enfermeiro $\left(E_{1}, E_{2}, ..\right)$, residente de enfermagem $\left(R_{1}, R_{2} ..\right)$, técnico de enfermagem $\left(T_{1}, T_{2}, \ldots\right)$ e auxiliar de enfermagem $\left(A_{1}, A_{2}, \ldots\right)$.

Esse material foi distribuído em um quadro, que demonstra, à esquerda, a fala dos entrevistados e, à direita, os subtemas (Quadro 1).

Mediante a leitura dos sub-temas, agrupamos os mesmos de acordo com sua familiaridade, surgindo assim, os temas.

Obtivemos, então, os seguintes temas e respectivos subtemas: identificando a dor no recém-nascido com os sub-temas manifestações

\begin{tabular}{|c|c|}
\hline Trechos das entrevistas & Sub-temas \\
\hline $\begin{array}{l}\text { Chora, faz caretinha(A5). } \\
\text { Ele chora, ele apresenta face de dor, ... (A4). } \\
\text { O choro e a expressão facial, pra mim são as duas principais (A6). }\end{array}$ & Manifestações dolorosas \\
\hline $\begin{array}{l}\text { Puncionar a veia, ... tirar esparadrapo(A4). } \\
\text { Punção venosa, coleta de sangue em geral, uma posição inadequada, uma manipulação excessiva, CPAP que a gente usa } \\
\text { muito aqui neles...(R1). }\end{array}$ & $\begin{array}{l}\text { Reconhecimento das situações dolorosas em } \\
\text { UCIN }\end{array}$ \\
\hline $\begin{array}{l}\text {... a gente faz uma vez por dia, então nem sempre naquele momento que a gente faz, a criança está com dor ou não né ... às } \\
\text { vezes no momento que a gente faz a criança está quietinha, tá dormindo, aí fica registrado lá "sem dor (E4). }\end{array}$ & Utilização de escalas de avaliação \\
\hline $\begin{array}{l}\text {...é a mudança de decúbito que a gente faz, é colocar a luvinha d'água , ...nossa parte a gente tem que fazer os } \\
\text { aconcheguinhos, quando dá pra colocar no RN, fazer os ninhozinhos...(A1). } \\
\text {...às vezes um vai e dá um dedo enluvado na hora de fazer um procedimento para a criança sugar...tem também diminuir a } \\
\text { luminosidade, o ruído, para ver se deixa as crianças mais tranqüilas (E1). }\end{array}$ & Intervenções não farmacológicas \\
\hline $\begin{array}{l}\text { Para dor, eles (médicos) prescrevem Dipirona EV, ou às vezes quando está muito agitado aí eles colocam Fentanyl, } \\
\text { Midazolan, depende (A5). } \\
\text {...se for uma criança no pós-operatório...coloca Fentanyl contínuo...outra vezes usa Dipirona de horário, outras usa } \\
\text { Dipirina só se for necessário (E1). }\end{array}$ & Intervenções farmacológicas \\
\hline $\begin{array}{l}\text { Acho que é você trabalhando no dia-a-dia mesmo, você começa a observar mais, você acaba observando o nenê e você vê } \\
\text { que ele tá com dor, porque quem tá mais tempo com o bebê é nós, nem tanto o médico, nem tanto a enfermeira, então é a } \\
\text { gente que vê e chama o colega de trabalho e fala - Você acha que o nenê tá com dor?...(A1). } \\
\text { A gente tem muito respaldo da Escola (EERP-USP), ... tem artigos, agora eu fui no Congresso e teve muita coisa sobre dor...(E1). }\end{array}$ & Fontes de informações \\
\hline
\end{tabular}

Quadro 1. Distribuição dos trechos das entrevistas e seus sub-temas. 


\begin{tabular}{|c|c|}
\hline Sub-temas & Temas \\
\hline Manifestações dolorosas & \multirow{3}{*}{$\begin{array}{l}\text { Identificando a dor no recém- } \\
\text { nascido }\end{array}$} \\
\hline Reconhecimento das situações dolorosas em UCIN & \\
\hline Utilização de escalas de avaliação & \\
\hline Intervenções não farmacológicas & \multirow{2}{*}{ Medidas de alívio da dor } \\
\hline Intervenções farmacológicas & \\
\hline Fontes de informações & $\begin{array}{l}\text { Obtendo conhecimento acerca } \\
\text { da dor }\end{array}$ \\
\hline
\end{tabular}

Quadro 2. Distribuição dos sub-temas e respectivos temas.

dolorosas, o reconhecimento de situações dolorosas em UCIN e utilização de escalas de avaliação da dor; medidas de alívio da dor , abrangendo os subtemas intervenções não farmacológicas e intervenções farmacológicas e obtendo conhecimento acerca da dor com o sub-tema fontes de informações.

\section{RESULTADOS}

\subsection{Identificando a dor no recém-nascido}

\subsubsection{Manifestações dolorosas}

A dor neonatal é reconhecida mediante alterações comportamentais e fisiológicas. Com relação às manifestações comportamentais, os profissionais identificaram a expressão facial e o choro em sua maioria, como podemos observar nos relatos a seguir:

O choro e a expressão facial, pra mim são as duas principais (A6).

O bebê extubado a primeira coisa é o choro, né, ele tenta se comunicar com você através do choro. $E$ antes disso tem as expressões faciais ...(E3).

Os entrevistados reconheceram como expressões faciais de dor a testa enrugada, os olhos fechados e a boca aberta:

Tem a expressão do rostinho mesmo, né, franzir a testinha, fechar o olhinho (A3).

... você vê a expressão da face, a boquinha entreaberta, o olhinho ... então você olha a face, o que eu acho muito importante é a testa franzida, ele franzi a testa...(E3).

Além da expressão facial e do choro, os entrevistados apontam outros indicadores comportamentais de dor, como a movimentação corporal (extensão e flexão dos membros superiores e inferiores), agitação e irritabilidade/desconforto, como descrito nas falas a seguir:

... Quando ele está sentindo dor, ele fica desconfortável, ele se mexe muito, fica agitado ... Agora quando ele está lá no respirador, ele se agita muito, fica muito agitado, se mexe muito, você vê que ele está com desconforto... Eu acho que é isso (T1).

Eles puxam a mão, quando a gente vai picar... (A10).

Eles ficam bem agitados ... eles agitam muito, principalmente braço e perna (E2).

Sobre as alterações fisiológicas, apenas 04 entrevistados (25\%) verbalizaram além das manifestações comportamentais, também as fisiológicas, como aumento das freqüências respiratória e cardíaca e diminuição da saturação de oxigênio. Estas foram abordadas em sua maioria pelas enfermeiras e em conjunto com as manifestações comportamentais, ou seja, não foram citadas isoladamente como sinais de dor:

...expressão facial, freqüência cardíaca aumentada, irritabilidade, testa enrugada (E1).

... as expressões faciais, altera (aumenta) todos os sinais vitais, freqüência cardiaca, respiratória ... Se a criança tá entubada, ai você vai mais pelos sinais vitais, pelo desconforto da criança, o estiramento dos membros... (E3).

Além de ficar choroso, tem os que alteram (diminui) a saturação, que agitam mais, eles ficam bem agitados... (A8).

Alguns profissionais relataram a questão da avaliação da dor em bebês entubados. Segundo eles, não é possível avaliar se uma criança entubada está com dor por meio do choro, devido a impossibilidade de escutar o som, mas percebe-se pela expressão facial que o RN simula o choro. Para eles, a expressão facial e a movimentação corporal são os sinais mais facilmente identificados nestas crianças:

O choro, mesmo quando o bebê está entubado tem a expressão do choro (A3).

Chora \{\} mesmo quando eles estão entubados fazem a carinha de dor né ..., se vê no rostinho deles que tá com dor né, que tá sofrendo (A8).

... às vezes nem chora, principalmente quando tá entubado a gente não escuta chorar, então eu vou pela fisionomia, ou então pela agitação (A7).

O grande desafio na avaliação da dor em lactentes pré-verbais, consiste em compreender a diferença do que é dor ou desconforto, para estabelecer assim, um correto diagnóstico de dor. Esta é uma das principais dificuldades da equipe de enfermagem, geralmente, devido a subjetividade da dor e pela falta de treinamento dos profissionais:

...você tem que saber distinguir ... tem que saber o que está dizendo o choro normalmente, ou então com as expressões, se ele tiver entubado, às vezes ele tá molhado, tá com fome, a criança chora muito por fome, aí você tem que saber também fazer esse diagnóstico com certeza né, se é dor ou não (E3).

\subsubsection{0 reconhecimento de situações dolorosas em UTIN}

Os profissionais entrevistados descreveram procedimentos invasivos e não invasivos como situações dolorosas para os RNs. Dentre os procedimentos invasivos, foram citados: punção venosa, intubação, aspiração, drenagem torácica, passagem de sonda e CPAP nasal. Em relação aos procedimentos dolorosos não invasivos, os entrevistados referiram: manipulação excessiva, toque brusco, posição desconfortável e retirada de esparadrapo, como identificado nos trechos das entrevistas a seguir:

Na hora da picadinha, na hora de aspirar, dependendo o jeito que você pega a criança, né (A5).

Puncionar a veia, ... tirar esparadrapo (A4).

... desde o toque que a gente dá nele ... com muita brutalidade, até um acesso venoso causa dor nele... (A7).

Punção venosa, coleta de sangue em geral, uma posição inadequada, uma manipulação excessiva, CPAP que a gente usa muito aqui neles... (R1).

... principalmente os cuidados invasivos né, punção venosa, drenagem de tórax, ... intubação endotraqueal... (E3). 
... também a passagem de sonda, deve ser horrivel (E1).

Um dos entrevistados apontou também, situações que causam desconforto e estresse ao RN, mas não dor, como: abertura da portinhola da incubadora, ruídos e conversas altas na enfermaria:

...você abre a incubadora, barulho que faz, a conversa alta \{\} eu acho que não seja assim uma dor, mais eu acho que incomoda, de alguma maneira não é bom para ele (A7).

\subsubsection{Utilização de escalas de avaliação da dor}

A escala de avaliação da dor utilizada no local estudado é a NIPS. Entretanto, quando as enfermeiras da UCIN aplicam esta escala no processo de Sistematização da Assistência de Enfermagem, a mesma não é usada corretamente, não sendo considerada eficaz e útil na prática clínica pela maioria dos profissionais, como expresso abaixo:

Acho que na prática ela (NIPS) não é útil, só ela isolada, acho que é muito pouco. Eu não sei se é da maneira que é feito, ou se realmente ela não funciona, porque muitas vezes você \{\} fala nossa essa criança tá com dor, aí você vai lá na avaliação (escala), que às vezes não fui eu que avaliei, foi outra pessoa, ai tá lá tudo zero os valores, e "sem dor", e você tá vendo que a criança tá com dor/.../As pessoas não avaliam direitinho, ou só avaliam naquele momento. E pode ser que naquele momento a criança não esteja com dor (E1).

... quando a gente vai fazer o processo, naquele momento a criança não está com dor, então a gente avalia como está "sem dor", mas na hora de um procedimento, o que acontece, ela vai sentir dor, ela muda né, ela tem a expressão no momento ... acho que é razoável (R1).

Além disso, alguns entrevistados questionam a questão do estresse e do desconforto serem confundidos com dor durante a utilização da escala e conseqüentemente ser estabelecido um diagnóstico de dor para a criança:

... às vezes você tem o diagnóstico de que a criança tá com dor e você tem a nítida impressão de que a criança está desconfortável por outro motivo, ou às vezes por fome, por outra coisa que não seja a dor. Então eu acho que a NIPS é uma escala que deixa muito a desejar (E3).

A escala NFCS foi acrescentada como uma complementação da NIPS, pois esta era insuficiente para avaliar a dor.

... ela (NIPS) deixa muita dúvida, tanto que nós introduzimos a NFCS, pra ver se a gente teria mais algum dado pra tá fazendo um diagnóstico melhor /.../ a gente encarou como uma complementação de dados, a gente faz primeiro a NIPS. Se deu alguma dúvida com a NIPS, a gente faz uma complementação com a NFCS. Com a NFCS a gente tem dados mais sensiveis, eu acho (E3).

\subsection{Manejo da dor}

\subsubsection{Medidas farmacológicas e não-farmacológicas para o alívio} da dor

Os entrevistados citaram inúmeras intervenções não-farmacológicas para 0 alívio da dor como o posicionamento adequado, a redução de estímulos ambientais e outras como a sucção não nutritiva e a administração de soluções, sendo o posicionamento adequado citado pela maioria dos profissionais.

Em relação ao posicionamento, os entrevistados identificaram como tal medida a mudança de decúbito, a posição fetal e o aconchego (mediante a confecção de ninhos e a utilização de luvas d'água) como descrito nas falas abaixo:

...posição de conforto, tem alguns que gostam de ficar mais embrulhadinho ou voltam à posição fetal... (E2).

...é você tentar deixar ela mais ou menos na posição intra-útero, que é a posição que eles preferem mais e aconchegar a criança, porque às vezes só com isso você consegue resolver um pouco o problema... (E3).

...é a mudança de decúbito que a gente faz, é colocar a luvinha d'água , ...nossa parte a gente tem que fazer os aconcheguinhos, quando dá pra colocar no RN, fazer os ninhozinhos... (A1).

Além do posicionamento, outras medidas como o contato pele-apele, o toque e a manipulação mínima foram apontados:

...pode ser pele-a-pele, uma conversa, ele pode não te responder, mas ele está te ouvindo (A6).

...eu acho que quando a gente coloca a mão em cima do paciente eles ficam mais seguros... (A10).

...o próprio toque na criança, para a organização dela (R1).

... ai a gente procura não manipular muito, desnecessariamente \{\} se você vê que a criança tá quieta, você já fez remédio pra dor, a gente procura deixar ela quieta, não ficar manipulando/.../ então aí usa fralda descartável, se você vê que não tá de cocô, não tá muito xixi, você não troca (T2).

Quanto aos estímulos ambientais, os profissionais citaram a redução da luminosidade e dos ruídos. Uma outra medida também descrita foi a sucção não-nutritiva, como identificada nas entrevistas abaixo:

...às vezes um vai e dá um dedo enluvado na hora de fazer um procedimento para a criança sugar...tem também diminuir a luminosidade, o ruído, para ver se deixa as crianças mais tranqüilas (E1).

...quando tá puncionando veia alguém faz sucção não-nutritiva, eu acho que acalma, com o dedo enluvado... (R2).

Em relação à administração de solução via oral, apenas um profissional, auxiliar de enfermagem, relatou sua utilização. Porém, esta ainda é uma medida em estudo na unidade.

...eles começaram a fazer agora um estudo que tá dando uma soluçãozinha antes na boquinha da criança, pra ela já tá tipo, sei lá acostumando...saber que depois dessa solução vai vir né, algum procedimento mais invasivo /.../ são sete dias, primeiro dia observa a criança sem fazer nada né, aí eu não sei se é no dia seguinte que começa a fazer a solução, ai passa, acho que, uns dois minutos, não me lembro, e faz o procedimento... eles gravam tudo, grava 0 bebê e anota a freqüência cardiaca durante o período, antes, durante e depois do procedimento ... (A10).

Com relação às intervenções farmacológicas, os profissionais identificaram alguns fármacos como Fentanyl ${ }^{\circledR}$, Midazolan ${ }^{\circledR}$ (Dormonid $\AA$ ) no pós-operatório e a Dipirona $\AA$ e o EMLA $\AA$ em procedimentos realizados na UCIN, sendo que o mais citado foi a Dipirona ${ }^{\circledR}$.

Para dor, eles (médicos) prescrevem Dipirona EV, ou às vezes quando está muito agitado aí eles colocam Fentanyl, Midazolan, 
depende (A5).

...se for uma criança no pós-operatório...coloca Fentanyl contínuo...outra vezes usa Dipirona de horário, outras usa Dipirina só se for necessário (E1).

Na verdade o Midazolan ele seda mas ele não tira a dor, quem tira a dor mesmo é o Fentanyl, então é associado o Midazolan, que é o Dormonid né, e o Fentanyl (E3).

Administrar medicamentos em horários corretos que são prescritos, antes de curativos, ...para minimizar a própria técnica, né, às vezes com a própria técnica, às vezes você consegue minimizar a dor que a criança vai sentir com o procedimento (R1).

\subsection{Fontes de informações}

Os entrevistados relataram que obtinham informações sobre a temática mediante orientações das equipes de enfermagem e médica, da troca de experiência entre os profissionais da equipe de enfermagem, das experiências adquiridas com o tempo de trabalho, das informações advindas da Escola de Enfermagem, através da Internet, além das palestras, artigos e trabalhos sobre dor.

A fonte mais utilizada pelos entrevistados foram as orientações das equipes médica e de enfermagem:

Acho que é você trabalhando no dia-a-dia mesmo, você começa a observar mais, você acaba observando o nenê e você vê que ele tá com dor, porque quem tá mais tempo com o bebê é nós, nem tanto 0 médico, nem tanto a enfermeira, então é a gente que vê e chama 0 colega de trabalho e fala - Você acha que o nenê tá com dor?... (A1).

Olha o pouco que eu sei é de orientação mesmo das enfermeiras, dos médicos, mas nunca li nada... (A7).

A gente tem muito respaldo da Escola (EERP-USP), ... tem artigos, agora eu fui no Congresso e teve muita coisa sobre dor... (E1)

\section{DISCUSSÃO}

Em relação à capacidade do $\mathrm{RN}$, a termo e pré termo sentirem dor, notou-se unanimidade em considerar que o paciente dessa faixa etária sente dor. Tal resultado indica uma mudança de paradigma que prevalecia até a década de 80 , em que o RN não era capaz de sentir dor ${ }^{(1)}$.

No momento de avaliar a dor, a maioria dos profissionais de enfermagem identificaram as manifestações comportamentais, e uma minoria identificou além destas, as manifestações fisiológicas, como situações possiveis de se perceber dor no RN.

Dentre as manifestações comportamentais, a dor neonatal pode ser identificada por meio da expressão facial, do choro, da movimentação corporal e do estado de sono-vigília( ${ }^{(8)}$, sendo a expressão facial, o choro e a movimentação corporal aqueles descritos nas entrevistas.

A expressão facial foi mencionada por todos os entrevistados. De fato, esta manifestação tem sido amplamente referida como índice de dor em bebês por enfermeiras ${ }^{(9,10)}$ e sua efetividade e confiabilidade como instrumento de avaliação da dor neonatal tem sido demonstrada por vários pesquisadores ${ }^{(11,12)}$.

$\mathrm{Na}$ face, há sinais específicos de dor como, fronte saliente, fenda palpebral estreitada, sulco naso-labial aprofundado, boca aberta, boca estirada (horizontal ou vertical), língua tensa, protrusão da língua e tremor de queixo ${ }^{(2)}$. Nos relatos, apenas três destas expressões faciais, a testa enrugada, os olhos fechados e a boca aberta foram reconhecidas, sendo as expressões faciais consideradas mais específicas e mais facilmente identificadas na dor neonatal(2).

Seguido da expressão facial, o choro foi citado por grande parte dos entrevistados para avaliar a dor do RN. Este achado corrobora com autores que demonstram, em seus estudos, o grande valor atribuído ao choro no momento da avaliação da dor do paciente pré-verbal| ${ }^{(9,10)}$. Entretanto, na prática sua utilização é muito questionável, visto que o choro pode ser desencadeado por outros estímulos como desconforto, fome e frio ${ }^{(13)}$, além da questão de RNs farmacologicamente comprometidos e entubados que são incapazes de vocalizar o choro(12).

Desse modo, o choro não fornece isoladamente informações para a decisão terapêutica a respeito da necessidade de analgesia na prática clínica(14). $^{(14)}$.

Com relação à atividade motora, estudos demonstram que RNs diante um estímulo doloroso apresentam movimentos de flexão e extensão das extremidades, rigidez do tórax, pescoço hiperestendido, movimentos abruptos e aleatórios da cabeça e do corpo ${ }^{(15,16)}$. Os entrevistados relatam a extensão e flexão dos membros superiores e inferiores, o tônus muscular, agitação e irritabilidade.

Poucos entrevistados descreveram os parâmetros fisiológicos para avaliar a dor do RN. Esse achado vai ao encontro de um estudo que demonstrou que as manifestações fisiológicas foram identificadas com menor freqüência pelas enfermeiras durante a avaliação da dor em $\mathrm{RNs}^{((9)}$.

Os entrevistados citaram o aumento das freqüências cardíaca e respiratória e diminuição da saturação de oxigênio como indicadores de dor. Sabe-se que além destes parâmetros fisiológicos existem outros como, aumento da pressão arterial, diminuição das pressões parciais de oxigênio e gás carbônico e aumento da sudorese palmar ${ }^{(8,14)}$.

As manifestações fisiológicas não foram descritas isoladamente pelos entrevistados, ou seja, foram abordadas em conjunto com as manifestações comportamentais. Estas manifestações não podem ser consideradas isoladamente, pois embora sejam objetivas, não são específicas, ou seja, elas podem também aparecer em situações estressantes, porém não dolorosas ${ }^{(14,17)}$.

Em relação ao reconhecimento de situações dolorosas em UCIN os relatos dos profissionais corroboram com estudos que consideram intervenções como punção venosa, intubação traqueal, aspiração de cânula traqueal, sondagem gástrica, entre outras, situações potencialmente promotoras de dor ${ }^{(18-20)}$.

Quanto à mensuração da dor, somente as enfermeiras e residentes de enfermagem utilizam escalas de avaliação da dor neste serviço, pois esta escala está inserida na Sistematização da Assistência de Enfermagem, documento preenchido somente por enfermeiras. As escalas utilizadas são a NIPS e a NFCS. Os profissionais apontaram alguns problemas com relação a aplicabilidade, confiabilidade e eficácia da NIPS na avaliação da dor. Questionaram o momento correto da sua utilização, pois referem usá-la somente uma vez ao dia e quando a aplicam o bebê pode não estar apresentando dor e vir apresentá-la posteriormente, não sendo conseqüentemente registrada. A avaliação da deve ser realizada a cada uma a três horas, de acordo com a gravidade do caso(21).

Outra questão relatada pelos entrevistados é a baixa especificidade da NIPS, pois eles acreditam que mesmo um bebê apresentando todos os sinais de dor da escala, pode não estar necessariamente com dor $\mathrm{e}$ sim com outro distúrbio como, estresse, fome ou desconforto.

Devido a essas dúvidas as enfermeiras optaram em utilizar a escala NFCS, como um instrumento coadjuvante na avaliação da dor. Inicialmente os profissionais avaliam a dor com a NIPS e posteriormente utilizam a NFCS para estabelecer um diagnóstico mais fidedigno. Um estudo realizado acerca da aplicação de escalas para avaliação da dor mostra que a NFCS parece ser mais sensível e específica do que a NIPS em RNs de diferentes idades gestacionais ${ }^{(22)}$.

Os entrevistados apresentam dúvidas acerca do correto diagnóstico 
de dor, devido a falta de conhecimento em relação à diferença entre a dor e o desconforto. Devido ao caráter subjetivo da dor é fundamental que haja um maior número de informações (manifestações de dor) possíveis, visto que comportamentos iguais podem ter conteúdos diversos e parâmetros fisiológicos podem refletir tanto dor como estresse ${ }^{(13)}$.

Para estes autores, é imprescindivel a utilização de métodos padronizados de avaliação da dor, para permitir uma mensuração mais sensivel e específica, reduzindo assim, o risco do subtratamento da dor nesta faixa etária.

Além do ponto de vista ético e humanitário, a dor do lactente préverbal deve ser considerada e tratada, visto que a dor aumenta a morbidade e a mortalidade, dificulta a restauração de processos mórbidos clínicos ou cirúrgicos, além de causar reorganização estrutural permanente e funcional das vias nervosas nociceptivas, que afetarão futuramente as experiências de dor da criança ${ }^{(13)}$.

As medidas de conforto relatadas pelos entrevistados como 0 posicionamento adequado, a manipulação mínima, redução da luminosidade e dos ruídos, vêem ao encontro de autores que as descrevem como sendo importantes para o cuidado desenvolvimental ${ }^{(23,24)}$. Estas medidas são efetivas para promover uma estabilidade e uma boa organização do neonato, podendo ser útil na conservação de energia para seu crescimento e desenvolvimento.

Quanto à realização do contato pele a pele, citado por um dos entrevistados, esta é uma medida que diminui a energia gasta pelo neonato e promove seu crescimento(24).

Em relação à utilização da sucção não-nutritiva, estudos mostram que é uma medida terapêutica indicada para a realização de pequenos procedimentos como a coleta de sangue, porém esta não reduz a dor, mas ajuda o recém-nascido a se organizar após o estímulo doloroso, minimizando as repercussões fisiológicas e comportamentais ${ }^{(14,25)}$. Quanto a esta medida, vale salientar que os entrevistados citaram apenas o dedo enluvado como sucção não-nutritiva e não a chupeta como relatam a maioria dos autores.

A administração de glicose ou sacarose em diferentes concentrações, com ou sem a suç̧ão não nutritiva, tem sido muito utilizada como intervenção não farmacológica para o alívio da dor ${ }^{(26-27)}$. Porém, das entrevistas realizadas apenas um dos profissionais da unidade citou sua utilização, não relatando, contudo, o tipo de solução administrada.

Além destas medidas, o agrupamento dos cuidados visando a manipulação mínima, foi relatado por apenas um dos profissionais, sendo de fundamental importância para um ótimo crescimento e desenvolvimento do recém-nascido.

Sobre a utilização de medidas farmacológicas observou-se que os profissionais conhecem as drogas mais comumente utilizadas, bem como a associação de sedação e analgesia quando necessária, como no caso de pós-operatório.

Um estudo acerca do tratamento farmacológico realizado por médicos demonstrou que menos de $10 \%$ dos entrevistados relataram o uso de analgesia para punções venosas e capilares; 30 a $40 \%$ referiram empregar analgésicos para punções lombares, dissecções venosas, drenagem de tórax e ventilação mecânica, e metade dos entrevistados relatou a aplicação de medidas de alívio da dor no pós-operatório de cirurgia abdominal em RNs. O medicamento mais utilizado foi o opióide $(60 \%)$ seguido pelo Midazolan $(30 \%)^{(4)}$.

Os autores reconhecem que os profissionais médicos demonstram, ainda, pouco conhecimento acerca da avaliação e tratamento da dor no período neonatal, havendo, então a necessidade de treinamento contínuo para os profissionais de saúde que atuam com esta população.

Observamos que a maioria dos entrevistados adquiriram informações somente por meio das orientações da equipe médica e de enfermagem, além das experiências do trabalho no dia-a-dia .

Foi possivel apreender nos relatos, o hábito pouco apurado para procura por publicações a respeito da dor nesta faixa etária.

As inúmeras publicações sobre a dor possibilita um melhor conhecimento por parte dos profissionais de saúde a respeito do assunto, além de recomendações formais em relação ao alívio da dor ${ }^{(4)}$.

\section{CONSIDERAÇÕES FINAIS}

A preocupação com a dor no período neonatal vem sendo motivada por estudos que demonstram desde a necessidade da avaliação correta da dor, mediante as alterações manifestadas por esta população, como também pelo uso adequado de medicamentos para sua redução ou alívio.

Os profissionais de saúde que atuam em UCINs demonstram conhecimento acerca das alterações apresentadas pelos RNs diante de situações dolorosas. Descrevem as manifestações mais comumente observadas e já validadas por pesquisadores. Reconhecem situações potencialmente dolorosas tais como punções venosas e intubação traqueal e também os tratamentos utilizados para redução ou alívio da mesma, quer sejam eles farmacológicos ou não.

Com relação à utilização de um instrumento para avaliação da dor, percebemos que os profissionais têm pouco conhecimento acerca do correto manuseio do mesmo, sendo aplicado em momentos nos quais o RN pode não estar manifestando sinais de dor. A dor deve ser considerada como $05^{\circ}$ sinal vital, devendo assim ser avaliada com mais freqüência nas UCINs.

Em virtude do caráter subjetivo da dor, torna-se necessário a utilização do maior número de informações possíveis, e não apenas o uso de um único instrumento.

A busca pelo conhecimento científico sobre dor em neonatos aparece somente nos relatos dos profissionais de nivel superior, no caso, os enfermeiros, sendo que os auxiliares e técnicos aprendem com a troca de experiências no cotidiano de trabalho ou com informações fornecidas por médicos e enfermeiros.

Acreditamos que o conhecimento científico deva ser introduzido na prática assistencial de maneira a ser absorvido por todos os profissionais que atuem com estes bebês, facilitando assim o acesso à literatura específica.

Existe, portanto, a necessidade de que os profissionais sejam capacitados adequadamente com relação a avaliação e manejo da dor, tornando-se multiplicadores de conhecimento para assim, poder desenvolver uma assistência integral, com qualidade e que reforce a intenção da promoção de um cuidado desenvolvimental ao recém-nascido em UCIN.

\section{REFERÊNCIAS}

1. Anand KJS, Phil D, Carr DB. The Neuroanatomy, neurophysiology, and neurochemistry of pain, stress, and analgesia in newborns and children. Pediatr Clin North Am 1989 aug; 36(4): 798-814.

2. Grunau RVE, Craig KD. Pain expression in neonates: facial action and cry. Pain 1987; 28:395-410.

3. Pereira ALST, Guinsburg R, Almeida MFB, Monteiro AC, Santos AMN, Kopelman BI. Validade de parâmetros comportamentais e fisiológicos para avaliação da dor aguda de recém-nascido a termo. São Paulo
Med J 1999 mar; 117(2). Disponível em: URL: http:// www. medico.org.br/especialidade/zac

4. Chermont AG, Guinsburg R, Balda RCX, Kopelman BI. O que os pediatras conhecem sobre avaliação e tratamento da dor no recémnascido? J Ped 2003; 79(3): 265-72.

5. Christoffel MM, Santos RS. A dor no recém-nascido e na criança. Rev Bras Enf 2001 jan-mar; 54(1): 27-33.

6. Minayo MCS. 0 desafio do conhecimento: pesquisa qualitativa em 
saúde. São Paulo (SP): Hucitec; 1992.

7. Bardin L. Análise de conteúdo. Lisboa (POR): Edições; 1977.

8. Guinsburg R. Dor no recém-nascido. In: Rugolo LMSS. Manual de Neonatologia - Sociedade de Pediatria de São Paulo. $2^{\mathrm{a}}$ ed. São Paulo (SP): Revinter; 2000. p. 63-8.

9. Shapiro CR. Nurse's judgments of pain in term and preterm newborns. JOGNN 1993 jan-feb; 22(1): 41-7.

10. Jones MA. Identifying signs that nurse interpret as indicating pain in newborns. Ped Nurs 1989 jan-feb; 15(1): 76-9.

11. Grunau RE, Oberlander T, Holstil L, Whitfield MF. Bedside application of the Neonatal Facial Coding System in pain assessment of premature neonates. Pain 1998 jun; 76(3): 277-86.

12. Stevens $B$, Johnston $C$, Petryshen $P$, Taddio A. Premature infant pain profile: development and initial validation. Clin J Pain 1996 mar; 12(1): 13-22.

13. Barbosa SMM, Guinsburg R. Dor de acordo com as faixas etárias pediátricas. Dor - Contexto Interdisciplinar. Maio; 2002.

14. Guinsburg R. Avaliação e tratamento da dor no recém-nascido. J Ped 1999; 75(3):149-52.

15. Pasero CL. Pain relief for neonates: watching for behaviour changes, subtles signals in theses vulnerable patients. Am J Nurs 2004 may; 104(5): 44-7.

16. Gardner SL. Pain and pain relief in the neonate. MCN. Am J Matern Child Nurs 1994 mar-apr; 19(2): 85-90.

17. Stevens BJ, Franck L. Special needs of preterm infants in the management of pain and discomfort. JOGNN 1995 nov-dec; 24(9): 856-62.

18. Santos JA, Procianoy RS, Bohrer BBA, Noer C, Librelato GAS,
Campleo JN. Os recém-nascidos sentem dor quando submetidos à sondagem gástrica? J Ped 2001; 77(5): 374-80.

19. Lindh V, Wiklund U, Sandman PO, Hakansson S. Assessment of acute pain in preterms infants by evaluation of facial expression and frequency domain analysis of heart are variability. Early Hum Dev 1997 apr; 48(1-2): 131-42.

20. Guinsburg R, Kopelman BI, Almeida MFB, Miyoshi MM. A dor do recém-nascido prematuro submetido a ventilação mecânica através de cânula traqueal. J Ped 1994; 70(2): 82-9.

21. Guinsburg R, Balda RCX. Dor em Neonatologia. Dor - Contexto Interdisciplinar. Maio; 2002.

22. Guinsburg R et al. Aplicação das escalas comportamentais para avaliação da dor em recém-nascidos. Brazilian Ped News 1999 set; 1(3). Disponivel em: URL: http:// www.brazilpednews.org.br/ setempp/ a099013

23. Stevens B, Johnston CC. Physiological responses of premature infants to a painful stimulus. Nurs Res 1994; 43(4): 226-31.

24. Byers JF. Components of developmental care and the evidence for their use in the NICU. MCN 2003; 28(3):175-180.

25. Gaiva MAM. Dor no recém-nascido: prática e conhecimentos atuais. Ped. Mod 2001; 37(5). Disponível em: URL: www.cibersaude.com.br/ index1.asp

26. Stevens B, Yamada J, Ohlsson A. Sucrose for analgesia in newborn infants undergoing painful procedures. Cochrane Database Syst Rev 2004(3):CD001069.

27. Stevens B, Yamada J, Ohlsson A. Sucrose for analgesia in newborn infants undergoing painful procedures. Cochrane Database Syst Rev 2001(4):CD001069. 